\title{
Türkiye’de Yolsuzluk ve Ekolojik Ayak İzi Arasındaki İlişkinin İncelenmesi
}

\section{Investigation of Relationship Between Corruption and Ecological Footprint in Turkey}

\author{
Ferda Nakıpoğlu Özsoy a,* \\ ${ }^{a}$ Dr. Öğretim Üyesi, Gaziantep Üniversitesi, İ̈BF, Küresel Siyaset ve Uluslararası İlişkiler Bölümü, Gaziantep/Türkiye. \\ ORCID: 0000-0002-5593-413X
}

\section{MAKALE BİLGISI}

Makale Geçmişi:

Başvuru tarihi: 01 Temmuz 2020

Düzeltme tarihi: 16 Şubat 2021

Kabul tarihi: 23 Şubat 2021

Anahtar Kelimeler:

Yolsuzluk

Ekonomik Büyüme

Çevresel Kuznets Eğrisi

\section{ARTICLE INFO}

\section{Article history:}

Received 01 Temmuz 2020

Received in revised form 16 February 2021

Accepted23 February 2021

\section{Keywords:}

Corruption

Economic Growth

Environmental Kuznets Curve
ÖZ

Çalışmada Türkiye'de 1995-2016 gözlem aralı̆̆ında kamudaki yolsuzluğun çevre kirliliği üzerindeki etkileri ARDL sınır testi yaklaşımı ile incelenmiş̧ir. Ekonomik büyümenin ekolojik ayak izi üzerindeki doğrusal etkilerinin yanı sıra olası parabolik ve kübik etkileri de incelenmiş, bu doğrultuda ekonomik büyüme ve ekolojik ayak izi arasındaki ilişki EKC hipotezi çerçevesinde test edilmiştir. Ayrıca dışa açıklık endeksi ve yolsuzluk endeksinin de çevre kirliliği üzerindeki etkileri araştırılmıştır. Kısa dönemde ekonomik büyüme ile çevre kirliliği arasında N-şeklinde bir ilişki tespit edilmiş; dışa açıklık endeksinin ekolojik ayak izi üzerinde negatif etkiye sahip olduğu ve yolsuzluğun ise çevre kirliliğini artırdığı sonucuna ulaşılmıştır. Uzun dönemde ekonomik büyüme ile çevre kirliliği arasında ters $\mathrm{N}$-şeklinde ilişki tespit edilmiş; dışa açıklık endeksi ve yolsuzluk değişkenlerinin katsayısının istatistiki olarak anlamsız olduğu sonucuna varılmıştır.

\section{A B S T R AC T}

In this study, the effect of the corruption in the public sector on environmental pollution is examined in Turkey during 1995-2016 by applying ARDL bounds testing approach. In addition to the linear effects of economic growth on the ecological footprint, possible parabolic and cubic effects are also examined, and the relationship between economic growth and ecological footprint is tested in the framework of the EKC hypothesis. In addition, the effects of trade openness index and corruption index on environmental pollution are investigated. In the short term, the N-shaped relationship has been detected between economic growth and environmental pollution. It is concluded that the trade openness index has a negative effect on the ecological footprint and corruption increases environmental pollution. In the long term, the inverse $\mathrm{N}$-shaped relationship has been found between economic growth and environmental pollution. It is concluded that the coefficient of trade openness index and corruption are statistically insignificant.

\section{Giriş}

Son yıllarda iklim değişikliği ve küresel ısınma sorunlarının temiz çevre bilincinin artmasına yol açtığı ve özellikle de iktisadi faaliyetlerin çevre kirliliği üzerindeki etkilerinin araştırıldığı önemli bir konu haline geldiği görülmektedir. Bu açıdan bakıldığında ekonomik büyüme ile çevre kirliliği arasındaki ilişkinin Çevresel Kuznets Eğrisi (EKC) çerçevesinde incelendiği ve bu çalışmalarda çeşitli politika önerilerinde bulunulduğu görülmektedir (Murthy ve Gambhir, 2018; Naz vd., 2019; Doğan ve Inglesi-Lotz, 2020; Ongan vd., 2020; Do ve Dinh, 2020). EKC hipotezi ile ekonomik büyümenin ilk aşamalarında çevresel tahribatın arttığı ancak belirli bir dönüm noktasından sonra ekonomik büyüme ile çevresel bilincin de oluşmasıyla çevre kalitesinin iyileştiği ve dolayısıyla ekonomik büyüme ile çevre kirliliği arasındaki ters-U şeklindeki ilişkinin söz konusu olduğu ifade edilmektedir (Panayotou, 1993).

EKC hipotezinin geçerliliği birçok araştırmacı tarafından çevresel tahribatın önemli bir göstergesi olan $\mathrm{CO} 2$ emisyonu ile araştırılsa da (Khan vd. 2016; Li vd., 2016; Ahmad vd., 2017; Özokcu ve Özdemir, 2017; Aslan vd., 2018; Balsalobre-Lorente vd., 2019; Ridzuan vd., 2020 Anser vd.

\footnotetext{
* Sorumlu yazar/ Corresponding author

e-posta: nakipoglu@gantep.edu.tr
} 
2020), Wackernagel ve Rees (1998) tarafından geliștirilen ve çevresel bozulma derecesini belirlemek için daha kapsamlı bir gösterge olarak kabul edilen ekolojik ayak izi ile ekonomik büyüme arasındaki ilişkiyi inceleyen çalışmalara da son zamanlarda ağırlık verildiği görülmektedir.

Çevresel tahribata yol açan unsurların incelendiği çalışmalara bakıldığında ağırlıklı olarak ekonomik büyümenin, dışa açıklık endeksinin ya da doğal kaynakların aşırı tüketimi sonucu ortaya çıkan kirliliğin etkileri araştırılırken, özellikle kamu kurumlarında sıklıkla karşılaşılan yolsuzluk kavramının ihmal edildiği görülmektedir. Yolsuzluk, kamu görevlilerinin kendilerine emanet edilen gücü kötüye kullanmaları nedeniyle yasa dışı bir şekilde kendilerini zenginleştirdikleri davranışları içermektedir (Transparency International, 2016). Bu kavram sadece iktisadi alanda değil aynı zamanda çevre ekonomisi alanında da kendinden söz ettirmeye başlamış bulunmaktadır. Özellikle gelişmekte olan ülkelerde önemli çevresel bozulma kaynağı olan yolsuzluğa dair literatür taraması 1970'lere dayansa da (Desai, 1998), çevre kirliliği ile olan ilişkisinin nicel değerlendirmelerine günümüzde odaklanılmaya başlanmıştır. Yolsuzluğun katı çevresel düzenlemeleri azaltabileceğine ve çevre kirliliğine neden olabileceğine dair görüşler söz konusu iken (Lopez ve Mitra, 2000), yolsuzluğun refahı düşürdüğü ve bunun neticesinde bazı gelir seviyelerinde düşük çevresel kirliliğe yol açarken bazı gelir düzeylerinde ise yüksek çevresel bozulmaya neden olabileceği (Grossman ve Krueger, 1995; Kaufmann vd., 1999) ifade edilmektedir. Gelir düzeyi arttıkça temiz çevre bilinci de artan toplumlar hükümetin çevresel düzenleme politikalarında değişikliğe gitmeleri yönünde baskıyı artırmakta ve böylelikle optimum çevre standartlarındaki uygulamalar daha katı hale gelmektedir. Diğer yandan sivil ve politik özgürlüklerde yaşanan artışlar da çevresel kaliteye verilen önemi artırmakta, dolayısıyla katı çevre politikaları yolsuzluktan etkilenmektedir (Damania et al., 2003). Bu doğrultuda yolsuzluğun sadece çevre yasalarının oluşturulmasında değil aynı zamanda bu yasaların uygulanmasındaki katılık nedeniyle çevre kirliliği üzerinde bir etkiye sahip olduğu da ifade edilmektedir (Hafner, 1998).

Bu doğrultuda çalışmanın amacı Türkiye'de 1995-2016 gözlem aralığı için yolsuzluk ve çevre kirliliği arasındaki ilişkinin incelenmesidir. Çalışmanın literatüre olan muhtemel katkısı şu şekildedir: i) Türkiye'de yolsuzluğun çevre kirliliği üzerindeki etkilerinin incelendiği ilk çalışma olduğu bilinmektedir. ii) Ampirik model oluşturulurken çevre kirliliği üzerindeki etkilerini göz önünde bulundurmak amacıyla ekonomik büyüme ve dișa açıklık endeksi değişkenleri de göz ardı edilmemiştir. iii) Yolsuzluk ve çevre kirliliği arasındaki ilişkinin incelendiği bu çalışmada ayrıca çevresel tahribatın önemli bir göstergesi olan ekolojik ayak izi ile EKC hipotezinin geçerliliği ARDL sınır testi yaklaşımı ile sınanmıştır. Çalışmanın geri kalanında öncelikle ekonomik büyüme, dışa açıklık endeksi, yolsuzluk ve çevre kirliliği arasındaki ilişki ile ilgili olarak literatür taramasına yer verilmiştir. Bir sonraki aşamada ampirik model, veri ve metodolojiden bahsedilip, ampirik bulgular aktarılmıştır. Son kısımda ise sonuç ve politika önerilerinde bulunulmuştur.

\section{Literatür}

Literatürde çevre kirliliğini etkileyen unsurların araştırıldığı birçok çalışma yer almakta ve bu çalışmaların en önemli özelliklerinin ağırlıklı olarak EKC hipotezinin geçerliliğini sınanmaları olduğu bilinmektedir. $\mathrm{Bu}$ çalışmada ise yolsuzluğun çevre kirliliği üzerindeki olası etkilerinin araştırılması ve EKC hipotezinin geçerliliğinin sınanması amaçlanmaktadır. $\mathrm{Bu}$ doğrultuda öncelikle ekonomik büyümenin ve dişa açıklık endeksinin çevre kirliliği üzerindeki etkilerinin araştırıldığı literatür taramasından bahsedilip, ardından yolsuzluk ve çevre kirliliği arasındaki ilişkinin incelendiği çalışmalara yer verilmiştir.

\subsection{Ekonomik Büyümenin ve Dışa Açıklık Endeksinin Çevre Kirliliği Üzerindeki Etkileri}

Ekonomik büyüme ve çevre kirliliği arasındaki ilişkinin incelendiği ve EKC hipotezinin test edildiği ilk ampirik çalışmalar Grossman ve Krueger (1991) ve Shafik ve Bandyopadhyay (1992) tarafından yapılmış, ardından bu çalışmaları takiben çeşitli araştırmalara yer verilmiştir. EKC hipotezinin geçerliliğini sınayan çalışmalardan elde edilen bulgular değerlendirildiğinde genellikle seçilen ülke grubunun, kullanılan değişkenlerin, periyot ya da yararlanılan ekonomik yöntemlerin farklılığından kaynaklı olarak çeşitli sonuçlarla karşılaşılmaktadır.

Öztürk ve Acaravcı (2013) 1960-2007 dönem aralığında Türkiye'de EKC hipotezinin geçerliliğini ARDL sınır testi yaklaşımı ile test etmiş, elde ettiği bulgular neticesinde ekonomik büyüme ve karbon emisyonu arasında ters Uşeklinde bir ilişkinin söz konusu olduğunu dolayısıyla Türkiye'de EKC hipotezinin varlığını ispatlamışlardır. Ayrıca dışa açıklık endeksinin kısa dönemde çevre kirliliği üzerinde herhangi bir etkisine rastlanılmazken, uzun dönemde çevre kirliliğini artırdığı sonucuna ulaşılmıştır. Cho vd. (2014) 22 OECD ülkesi için 1971-2000 yıllarında ekonomik büyüme ve karbon emisyonu arasında ters Uşeklinde bir ilişki tespit etmiş; Lau vd., (2014) ise 1970-2008 döneminde Malezya'da hem kısa hem de uzun dönemde EKC hipotezinin geçerli olduğu sonucuna ulaşmış ve dişa açıklık endeksinin karbon emisyonunu artırdığını dolayısıyla çevre kalitesinde bozulmaya neden olduğunu ifade etmiştir. Destek ve Özsoy (2015) 1970-2010 dönemi, Bölük ve Mert (2015) ise 1961-2010 yılları için Türkiye'de ARDL sınır testi yaklaşımı ile inceledikleri ekonomik büyüme ve karbon emisyonu arasındaki ilişkiye dair ters U-şeklinde bir iliş̧kinin varlığını tespit etmişlerdir. Kasman ve Duman (2015) AB ülkelerinde 1992-2010 gözlem aralığında EKC hipotezinin geçerli olduğunu ve ticaret hacminde meydana gelen bir artışın karbon emisyonu üzerinde olumsuz bir etkiye sahip olduğu sonucuna ulaşmıştır. Doğan ve Turkekul (2016) ise 1960-2010 döneminde ARDL sınır testi yaklaşımı ile incelediği ekonomik büyüme-karbon emisyonu arasındaki ilişkiye dair elde ettiği bulgular neticesinde ABD'de EKC hipotezinin geçerli olmadığını bulmuştur. Ayrıca dışa açıklık endeksi katsayısı kısa dönemde istatistiki olarak anlamsız iken, uzun dönemde karbon emisyonunu azalttığına dair bulgular elde etmiştir. Benzer şekilde Destek vd. (2016) seçili Orta ve Doğu Avrupa Ülkeleri'nde 1991-2011 dönem aralığında EKC hipotezinin varlığının geçerli olduğunu tespit etmiş ve dişa açıklık endeksinde meydana gelen bir artışın karbon emisyonunu azalttığına dair bulgular elde etmişlerdir. Zhang vd. (2017) 10 yeni sanayileşmiş ülke için 
1971-2013 döneminde EKC hipotezinin geçerliliğini sınamış ve elde edilen bulgular neticesinde ekonomik büyümede meydana gelen bir artışın öncelikle çevresel tahribata yol açtığını ancak belirli bir dönüm noktasından sonra çevresel kalitenin arttığına dair bulgular elde etmişlerdir. Ayrıca dışa açıklık endeksinin karbon emisyonu ile negatif yönlü bir ilişkiye sahip olduğunu, çevre kalitesini iyileştirdiğini ifade etmişlerdir. Çetin vd. (2018) Türkiye için 1960-2013 gözlem aralığında EKC hipotezinin geçerli olduğunu ve dışa açıklık endeksi katsayısının pozitif işaretli ve istatistiki olarak anlamlı olduğunu dolayısıyla dışa açıklık endeksinin çevresel tahribata yol açtığını tespit etmişlerdir. Pata (2019) Türkiye'de 1969-2017 yıllarında ekonomik büyüme ve karbon emisyonu arasında ters U-şeklinde ilişkinin olduğunu tespit etmiş, dışa açıklık endeksinin ise karbon emisyonu üzerinde artırıcı bir etkisinin söz konusu olduğunu ifade ederken Do ve Dinh (2020) ise dişa açıklık endeksinin karbon emisyonunu azalttığı yönünde bulgular elde etmiştir. Kılavuz ve Doğan (2020) Türkiye'de 1961 2018 gözlem aralığında ekonomik büyüme ve dışa açıklık endeksinin çevre kirliliği üzerindeki etkilerini inceledikleri çalışmalarında uzun dönemde EKC hipotezinin geçerli olduğunu tespit ederken, dışa açıklık endeksinin karbon emisyonu ile uzun dönemde pozitif yönlü bir ilişkiye sahip olduğunu ancak istatistiki olarak anlamsız bir sonuç elde edildiğini belirtmişlerdir. Benzer şekilde Uzar ve Eyuboğlu (2020)'da 1975-2017 yıllarında Türkiye'de EKC hipotezinin geçerli olduğu sonucunu elde ederken dişa açıklık endeksinin karbon emisyonu üzerinde pozitif yönlü ancak istatistiki olarak anlamsız bir etkiye sahip olduğu sonucuna ulaşmışlardır. Kahia vd. (2021) 1990-2016 döneminde Suudi Arabistan'da EKC hipotezinin geçerliliğinin sadece sıvı yakıt tüketiminden kaynaklanan $\mathrm{CO} 2$ emisyonları için desteklendiğini, dışa açıklık endeksinin ise karbon emisyonu üzerinde pozitif yönlü bir etkiye sahip olduğunu tespit etmişlerdir.

Literatürde ekonomik büyüme ve karbon emisyonu arasındaki ilişkinin incelendiği çalışmaların yanı sıra çevresel bozulma derecesini belirlemek için daha geniş kapsamlı olarak kabul edilen ekolojik ayak izi ile ekonomik büyüme arasındaki ilişkinin incelendiği çalıșmalara da rastlamak mümkündür. Bu çalışmalardan bazıları Tablo 1'de gösterilmektedir.
Tablo 1. EKC Hipotezinin Geçerliliğinin Ekolojik Ayak İzi ile Sınandığı Literatür Özeti

\begin{tabular}{|c|c|c|c|}
\hline Çalışma & $\begin{array}{ll}\text { Ülke } & \text { ve } \\
\text { Dönem } & \\
\end{array}$ & Yöntem & Bulgular \\
\hline $\begin{array}{l}\text { Al-Mulali } \\
\text { vd. (2015) }\end{array}$ & $\begin{array}{l}93 \text { ülke } \\
1980-2008\end{array}$ & Panel GMM & $\begin{array}{l}\text { EKC hipotezi } \\
\text { düşük gelirli ve } \\
\text { alt orta gelirli } \\
\text { ülkelerde } \\
\text { geçerli } \\
\text { değilken, } \\
\text { yüksek gelirli } \\
\text { ve üst orta } \\
\text { gelirli ülkelerde } \\
\text { geçerlidir }\end{array}$ \\
\hline Hervieux ve & $7 \quad$ Latin & Zaman serisi & EKC hipotezi \\
\hline $\begin{array}{l}\text { Darné } \\
(2015)\end{array}$ & $\begin{array}{l}\text { Amerika } \\
\text { ülkesi } \\
1961-2007\end{array}$ & $\begin{array}{l}\text { eşbütünleşme } \\
\text { testi }\end{array}$ & geçerli değildir \\
\hline $\begin{array}{l}\text { Öztürk vd. } \\
(2016)\end{array}$ & $\begin{array}{l}144 \text { ülke } \\
1988-2008\end{array}$ & $\begin{array}{l}\text { Zaman serisi } \\
\text { GMM, } \\
\text { S-GMM }\end{array}$ & $\begin{array}{l}\text { EKC hipotezi } \\
\text { düşük gelirli ve } \\
\text { alt orta gelirli } \\
\text { ülkelerde } \\
\text { geçerli } \\
\text { değilken, } \\
\text { yüksek gelirli } \\
\text { ve üst orta } \\
\text { gelirli ülkelerde } \\
\text { geçerlidir }\end{array}$ \\
\hline $\begin{array}{l}\text { Al-Mulali } \\
\text { vd. (2016) }\end{array}$ & $\begin{array}{l}58 \text { ülke } \\
1980-2009\end{array}$ & $\begin{array}{l}\text { Panel FE ve } \\
\text { GMM }\end{array}$ & $\begin{array}{l}\text { EKC hipotezi } \\
\text { geçerli değildir }\end{array}$ \\
\hline $\begin{array}{l}\text { Mrabet ve } \\
\text { Alsamara } \\
\text { (2017) }\end{array}$ & $\begin{array}{l}\text { Katar } \\
1980-2011\end{array}$ & ARDL & $\begin{array}{l}\text { EKC hipotezi } \\
\text { geçerlidir }\end{array}$ \\
\hline $\begin{array}{l}\text { Charfeddine } \\
\text { ve Mrabet } \\
\text { (2017) }\end{array}$ & $\begin{array}{l}15 \text { MENA } \\
\text { ülkesi } \\
\text { 1995-2007 }\end{array}$ & $\begin{array}{l}\text { Panel } \\
\text { FMOLS } \\
\text { Panel DOLS }\end{array}$ & $\begin{array}{l}\text { EKC hipotezi } \\
\text { geçerlidir }\end{array}$ \\
\hline $\begin{array}{l}\text { Ulucak ve } \\
\text { Bilgili } \\
\text { (2018) }\end{array}$ & $\begin{array}{l}\text { Yüksek, orta } \\
\text { ve düşük } \\
\text { gelirli } \\
\text { ülkeler } \\
\text { 1961-2013 }\end{array}$ & $\begin{array}{l}\text { CUP-FM } \\
\text { CUP-BC }\end{array}$ & $\begin{array}{l}\text { EKC hipotezi } \\
\text { geçerlidir }\end{array}$ \\
\hline $\begin{array}{l}\text { Destek vd. } \\
(2018)\end{array}$ & $\begin{array}{l}\text { EU ülkeleri } \\
1980-2013\end{array}$ & $\begin{array}{l}\text { Panel } \\
\text { FMOLS } \\
\text { Panel DOLS } \\
\text { DCCE }\end{array}$ & $\begin{array}{l}\text { Portekiz için } \\
\text { EKC hipotezi } \\
\text { geçerlidir }\end{array}$ \\
\hline $\begin{array}{l}\text { Destek ve } \\
\text { Sarkodie } \\
(2019)\end{array}$ & $\begin{array}{l}11 \quad \text { yeni } \\
\text { sanayileşmiş } \\
\text { ülke } \\
1977-2013\end{array}$ & $\begin{array}{l}\text { AMG } \\
\text { tahmincisi } \\
\text { Panel } \\
\text { Nedensellik }\end{array}$ & $\begin{array}{l}\text { EKC hipotezi } \\
\text { geçerlidir }\end{array}$ \\
\hline $\begin{array}{l}\text { Ulucak ve } \\
\text { Khan } \\
(2020)\end{array}$ & $\begin{array}{l}\text { BRICS } \\
\text { ülkeleri } \\
\text { 1992-2016 }\end{array}$ & $\begin{array}{l}\text { Panel } \\
\text { FMOLS } \\
\text { DOLS }\end{array}$ & $\begin{array}{l}\text { EKC hipotezi } \\
\text { geçerlidir }\end{array}$ \\
\hline $\begin{array}{l}\text { Y1lanc1 ve } \\
\text { Pata (2020) }\end{array}$ & $\begin{array}{l}\text { Çin } \\
1965-2016\end{array}$ & $\begin{array}{l}\text { Fourier } \\
\text { ARDL }\end{array}$ & $\begin{array}{l}\text { EKC hipotezi } \\
\text { geçerli değildir }\end{array}$ \\
\hline
\end{tabular}

\subsection{Yolsuzluk ve Çevre Kirliliği Arasındaki İlişki}

S1k1 çevre koruma politikalarında ortaya çıkan esneklikler, tercih edilen şirketlere aşırı avantaj sağlama ya da özellikle gelişmekte olan ekonomilerde sanayileşme sonrası çevre koruma politikalarının ikinci plana atılması gibi nedenlerin yolsuzluk uygulamalarına neden olduğu görüşü savunulmaktadır. Diğer yandan çevre koruma yasalarının sıkı yönetiminden kaynaklı aksaklıkların çevresel tahribatla ilişkili olabileceğini ortaya koyan çalışmalar da mevcuttur (Lucas vd., 1992; Rodriguez vd., 2005). Ayrıca Lippe (1999) yolsuzluk ve çevre kirliliği arasındaki ilişkiyi inceleyerek yolsuzluğun çevre yasalarının uygulanmasında etkinsizliğe 
neden olarak çevre kirliliğine yol açabileceğini ifade etmiştir.

Lopez ve Mitra (2000) tüm dünyada yolsuzluğun yaşandığını ancak özellikle gelişmekte olan ülkelerde kamu kurumlarının genellikle ekonomik verimliliğin sağlanmasında etkili olamadığını, rüşvet ve yolsuzluk olaylarının sıklıkla yaşandı̆̆ını ve bunların birer sonucu olarak da devlet kurumlarında ve çevresel düzenlemelerde etkinliğin zayıfladığını ifade etmektedir. Bu nedenle birçok kesimde çevresel maliyet artışlarından kaçınmak için daha ucuz yolların tercih edilmesi, yasa dişı uygulamalara başvurulması kirlilik kontrol yasalarının uygulanmasında engel oluşturduğu belirtilmiştir. Fredriksson vd. (2004) 1982-1996 gözlem aralığında 12 OECD ülkesinde çevre kirliliği ve yolsuzluk ilişkisini incelediği çalışmasında yüksek yolsuzluk seviyesinin daha düşük enerji etkinliğine sebep olduğu sonucuna ulaşmıştır. Welsch (2004) 122 ülke için 1980-1997 döneminde çevre kirliliğinin yolsuzluk döneminde monotonik bir şekilde artış gösterdiği sonucuna ulaşmıştır.

Pearse (2016) yolsuzluk uygulamalarının ülkelerin ekonomik dinamiklerini etkilediğini dolayısıyla çevresel bozulmayı etkileyebileceğini belirtmiş, özellikle emisyon ticaretinde yaşanılacak bir yolsuzluk uygulamasının doğrudan çevresel tahribata sebep olabileceğini ifade etmiştir. Chen vd. (2018) Çin'de yolsuzlukta meydana gelecek bir artışın çevresel düzenlemelerdeki etkinliği azalttığı sonucuna ulaşırken, bu duruma çevresel düzenlemelerdeki zayıflığın nedeniyle yasadışı üretimin artacağı ve kirletici emisyonların salınımına sebep olacağı ifade edilmektedir. Diğer yandan Balsalobre-Lorente vd. (2019) 16 seçili OECD ülkesinde yolsuzluğun karbon emisyonu üzerindeki etkisini araştırmış ve yolsuzluğun uzun dönemde çevre kalitesini olumsuz etkilediği sonucuna ulaşmıştır. Ayrıca Sinha vd. (2019) gelecek 11 ülke (Next11) ile BRICS ülkelerinde 1990-2017 dönem aralığında yolsuzluğun kamu sektörü üzerindeki etkilerini incelemiş, yolsuzluğun yenilenebilir enerji tüketiminin çevre kalitesi üzerindeki olumlu etkisini azaltarak ve fosil yakıt tüketiminin olumsuz etkisini artırarak çevresel bozulmayı arttırdığ 1 sonucuna ulaşmıştır. Seçilen ülke gruplarının büyüme potansiyeline sahip olma özelliklerinden dolayı elde edecekleri avantajlardan yararlanmak yerine ülkelerdeki kamu sektöründe yaşanan yolsuzluk uygulamalarından olumsuz etkilendikleri ifade edilmektedir. Kamu sektöründe yolsuzluk olması durumunda yenilenebilir enerji kullanımına yönelik girişimlerin karbon emisyonunu azaltmada etkili olamayacağını ifade eden çalışmada kalkınmanın olgunlaştığı ve kurumsallaşmanın daha katı olduğu ülkelerde, yolsuzluk uygulamalarına daha eğilimli olduğu ortaya konulmuştur.

\section{Model, Veri ve Metodoloji}

Türkiye'de yolsuzluğun çevre kirliliği üzerindeki etkisinin incelendiği bu çalışmada, EKC hipotezi çerçevesinde çevre kirliliği ve ekonomik büyüme arasındaki ilişkiyi de göz ardı etmemek amacıyla oluşturulan ampirik model;

$\operatorname{InE} F_{t}=\delta_{0}+\delta_{1} \operatorname{InY}_{t}+\delta_{2} \operatorname{InY}_{t}^{2}+\delta_{3} \operatorname{In} Y_{t}^{3}+\operatorname{InCor}_{t}+$ $\operatorname{InT} T_{t}+\mu_{t}$

şeklindedir. 1 numaralı denklemde yer alan değişkenlerden $\operatorname{InEF}$, ekolojik ayak izinin doğal logaritmasını; In $Y$, kişi başına reel GSYİH'nın doğal logaritmasını; $\operatorname{In} Y^{2}$ ve $\operatorname{In} Y^{3}$, kişi başına reel milli gelirin doğal logaritmasının karesini ve küpünü; InCor, yolsuzluk endeksinin doğal logaritmasını; InT, dışa açıklık endeksinin doğal logaritmasını ve $\mu_{t}$, hata terimini ifade etmektedir. InEF serisi Wackernagel ve Rees'in (1998)'in de belirttiği üzere ekili alanı, otlak arazisini, balıkçılık alanını, ormanlık alanı, karbon ayak izini ve yerleşik arazileri dikkate alması nedeniyle çevresel bozulmanın derecesini belirlemek için daha kapsamlı bir gösterge olarak kabul edilmektedir. InCor serisi ise 1 (düşük) ile 6 (yüksek) arasında değer alan kamu sektöründe şeffaflığı, hesap verebilirliği ve yolsuzluk kapsamını değerlendiren bir göstergedir. Modelde, InY serisi 2010 yılı sabit fiyatlarıyla dolar cinsinden, InT serisi ise GSYİH içindeki toplam ticaretin payı olarak kullanılmıştır. Çalışmada yararlanılan reel GSYİH ve dışa açıklık endeksi verileri World Development Indicators (World Bank, 2016), ekolojik ayak izi verileri Global Footprint Network (Global Footprint Network, 2017) ve yolsuzluk endeksi verileri ise Transparency International (Transparency International, 2016) veri tabanından elde edilmiştir. 1995-2016 dönemindeki yıllık serileri kapsayan çalışmanın en önemli kısıtı ekolojik ayak izi verisinin eksikliğinden kaynaklanmaktadır. Diğer yandan modelde yer alan değişkenlerin tanımlayıcı istatistikleri Tablo 2'de gösterilmektedir.

Çalışmada kişi başına reel GSYİH, yolsuzluk, dışa açıklık ve ekolojik ayak izi arasındaki uzun dönemli ilişkinin varlığı otokorelasyon ve içsellik sorunlarına karşı tutarlı sonuçlar veren (Pesaran ve Shin, 1998) ARDL sınır testi yaklaşımı ile incelenmiştir. $\mathrm{Bu}$ test farklı düzeylerde bütünleşik olan seriler arasındaki uzun dönemli ilişkinin test edilmesine imkan sunması ve seriler arasındaki kısa dönemli uyarlanma süreci ile uzun dönemli ilişkinin ayrıştırılabilmesine imkan tanıması (Pesaran ve Shin, 1998) açısından avantajlıdır. Ayrıca tahmin aralığı kısa olan serilerin uzun dönemli tahminlerinde de güvenilir sonuçlar veren ARDL sınır testi yaklaşımının ampirik modeli şu şekildedir:

$d \ln E F_{t}=c_{0}+\sum_{i=1}^{n} \beta_{0, i} \operatorname{InEF} F_{t-i}+\sum_{i=1}^{n} \beta_{1, i} d \operatorname{In} Y_{t-i}+$ $\sum_{i=1}^{n} \beta_{2, i} d \operatorname{In} Y_{t-i}^{2}+\sum_{i=1}^{n} \beta_{3, i} d \operatorname{In} Y_{t-i}^{3}+$ $\sum_{i=1}^{n} \beta_{4, i} d \operatorname{InC} \operatorname{Cor}_{t-i}+\sum_{i=1}^{n} \beta_{5, i} d \operatorname{InT} T_{t-i}+\delta_{0} \operatorname{InEF}_{t-1}+$ $\delta_{1} \operatorname{InY}_{t-1}+\delta_{2} \operatorname{InY}_{t-1}^{2}+\delta_{3} \operatorname{InY}_{t-1}+\delta_{4}$ InCor $_{t-1}+$ $\delta_{5} I n T_{t-1}+\mu_{t}$

2 numaralı denklemde yer alan $d$, fark alınan durumu ifade ederken; $n$ ise gecikme sayısını temsil etmektedir. Alt ve üst sınırı belirleyen $\mathrm{F}$ istatistiği $\delta_{0}, \delta_{1}, \delta_{2}, \delta_{3}, \delta_{4}$ ile ortak anlamlılıklarını sınamak için hesaplanmaktadır. Diğer yandan değişkenler arasındaki uzun dönemli ilişkinin söz konusu olmadığını ifade eden boş hipotez $H_{0}: \delta_{0}=\delta_{1}=$ $\delta_{2}=\delta_{3}=\delta_{4}=0$ iken alternatif hipotez $H_{0}: \delta_{0} \neq \delta_{1} \neq$ $\delta_{2} \neq \delta_{3} \neq \delta_{4} \neq 0$ şeklindedir.

\section{Ampirik Bulgular}

Çalışmada ampirik bulgulardan elde edilen sonuçlar aktarılmadan önce modelde kullanılan değişkenlere ait tanımlayıcı istatistiklerinin özetine Tablo 2'de yer verilmiştir. 
Tablo 2. Tanımlayıcı İstatistikler

\begin{tabular}{lcccccc}
\hline & LEF & LY & LY2 & LY3 & LCOR & LTR \\
\hline Ortalama & 21.714 & 21.330 & 456.280 & 9788.037 & 1.359 & 22.068 \\
Maks. & 21.945 & 22.995 & 528.751 & 12158.40 & 1.610 & 22.427 \\
Mini. & 19.480 & 18.606 & 346.193 & 6441.367 & 1.131402 & 19.938 \\
Standart S. & 0.508 & 1.167 & 49.834 & 1601.864 & 0.143 & 0.694 \\
\hline
\end{tabular}

Tablo 2'de modelde kullanılan değişkenlere ait tanımlayıcı istatistikler gösterilmektedir. Türkiye'de 1995-2016 yılları arasında ortalama ekolojik ayak izi 21.714 olarak görülürken, aynı dönemde kişi başına düşen reel GSYİH değerinin 21.330 dolar (2010 yılı sabit fiyatlarıyla) olduğu bilinmektedir. Yolsuzluk için maksimum değer 1.610 iken en düşük değer 1.131'dir. Diğer yandan dişa açıklık endeksi aynı dönemde en yüksek değer olarak 22.427 iken en düşük değeri 19.938 'dir.

Çalışmada serilerin durağanlık özellikleri Augmented Dickey-Fuller (ADF) birim kök testi aracılığı ile sınanmış ve elde edilen bulgular Tablo 3'te gösterilmiştir. ADF birim kök testi sonuçlarına göre tüm değişkenler düzey değerde birim kök içerirken, serilerin fark değerlerinin alınmasıyla tüm değişkenlerin durağan hale geldikleri ve serilerin durağan olmadığını ifade eden $\mathrm{H}_{0}$ hipotezinin reddedildiği görülmektedir.

Tablo 3. ADF Birim Kök Testi

\begin{tabular}{lllll}
\hline \multicolumn{3}{c}{ Augmented Dickey-Fuller (ADF) Test } \\
\hline Değişkenler & \multicolumn{3}{c}{ Düzey } & \multicolumn{2}{c}{ Birinci Derece } \\
\cline { 2 - 5 } & Sabit & $\begin{array}{l}\text { Sabit\& } \\
\text { Trend }\end{array}$ & Sabit & $\begin{array}{l}\text { Sabit\& } \\
\text { Trend }\end{array}$ \\
InEF & -2.408 & -1.865 & -5.257 & -5.122 \\
& $(0.154)$ & $(0.628)$ & $(0.000)$ & $(0.003)$ \\
InY & -1.865 & -2.072 & -4.031 & -3.911 \\
& $(0.340)$ & $(0.529)$ & $(0.006)$ & $(0.032)$ \\
InTR & -2.590 & -2.378 & -5.019 & -4.920 \\
& $(0.114)$ & $(0.376)$ & $(0.001)$ & $(0.004)$ \\
InCOR & -1.897 & -2.668 & -3.691 & -3.505 \\
& $(0.327)$ & $(0.258)$ & $(0.013)$ & $(0.067)$ \\
\hline
\end{tabular}

Not: Parantez içindeki değerler olasılık değerleridir

Seriler arasındaki uzun dönemli ilişkinin test edilmesi amacıyla yapılan eşbütünleşme testi sonuçları Tablo 4'te gösterilmektedir. Elde edilen ARDL model tahmincisi sonuçlarına göre F-istatistiği \%1 anlamlılık düzeyinde üst sınır kritik değerinin üzerinde olması nedeniyle serilerin eşbütünleşik olduğu ve dolayısıyla seriler arasında uzun dönemli ilişkinin geçerli olduğu sonucuna ulaşılmıştır. Tablo 4. ARDL Model Tahmincisi

Tahmin edilen model Optimal gecikme uzunluğu F-ist.

\begin{tabular}{l|l|l}
\hline$E F_{t}$ & $3,1,1,1,0,1$ & $10.016^{* * *}$ \\
$=\left(Y_{t} Y^{2}{ }_{t} Y^{3}{ }_{t} \operatorname{Cor}_{t} T_{t}\right)$ & Critical values & \\
Alt Sınır $I_{0}$ & & Üst Sınır $I_{1}$ \\
$\% 10: 2.41$ & & $\% 10: 3.52$ \\
$\% 5: 2.91$ & & $\% 1: 5.19$ \\
$\% 1: 4.13$ & & \\
& & \\
\hline
\end{tabular}

Not: ***, \%1 düzeyinde istatistiki olarak anlamlıdır. Kritik değerler Narayan (2005)'ten alınmıştır.

Seriler arasındaki uzun dönemli ilişkinin geçerli olduğu sonucuna ulaşıldıktan sonra değişkenlerin kısa ve uzun dönemli katsayıları incelenmiş ve elde edilen bulgulara Tablo 5'te yer verilmiştir. Değişkenlerin kısa dönemli katsayılarına dair elde edilen bulgular değerlendirildiğinde, reel GSYİH'nın katsayısının ekolojik ayak izi üzerinde pozitif, reel GSYİH'nın karesinin ekolojik aya izi üzerinde negatif ve reel GSYİH'nın küpünün ise pozitif etkiye sahip olduğu sonucuna ulaşılmıştır. Bu doğrultuda reel GSYİH ile ekolojik ayak izi arasında N-şeklinde bir ilişki olduğu tespit edilmiştir. Yolsuzluk katsayısının ekolojik ayak izi üzerinde pozitif bir etkiye neden olduğu dolayısıyla yolsuzluğun çevresel tahribata yol açtığı sonucuna varılmıştır. Diğer yandan dışa açıklık endeksi katsayısının negatif ve istatistiki olarak anlamlı olması ekolojik ayak izini azalttığını ifade etmektedir. Benzer şekilde Zhang vd. (2017) özellikle gelişmekte olan ülkelerde dişa açıklık endeksinin çevre kirliliği üzerinde pozitif yönlü bir etkisini beklerken elde edilen ampirik bulgular neticesinde dişa açıklık endeksinin çevre kalitesini iyileştirdiğini tespit etmişlerdir. Bunun nedeni olarak ise 10 yeni sanayileşmiş ülkenin temiz üretime ağırlık vermeleri, kirletici işletmelerin ihracatına müdahale edilmesi ve diğer ülkelerden temiz mal ve hizmet ithalatını teşvik etmeleri gösterilmektedir. Diğer yandan Sinha vd. (2019)'da dışa açıklık endeksinin çevre kirliliğini azalttığı sonucuna ulaşmıştır. Ayrıca ekolojik ayak izinde meydana gelebilecek bir şokun uyarlanma sürecini ifade eden hata terimi katsayısının negatif işaretli ve istatistiki olarak anlamlı olması ve bağımlı değişkende meydana gelen bir şokun yaklaşık bir yılda giderileceğine dair bulgular elde edilmiştir. Uzun dönemli katsayılar incelendiğinde ise kısa dönemli katsayı sonuçlarından farklı olarak reel GSYİH'nın ekolojik ayak izi üzerinde negatif, reel milli gelirin karesinin pozitif ve reel GSYİH'nın küpünün ise negatif işaretli olması sonucu reel GSYİH ile ekolojik ayak izi arasında ters Nşeklinde bir ilişkinin söz konusu olduğu sonucuna varılmış; Sinha vd. (2019)'nin Gelecek-11 ve BRICS ülkelerinde ters $\mathrm{N}$-şeklindeki ilişkinin varlığını tespit ettikleri çalışma ile paralel bir sonuç elde edilmiştir. Diğer yandan uzun dönemde yolsuzluk endeksi katsayısının pozitif işaretli ancak istatistiki olarak anlamsız olduğu sonucu tespit edilmiştir. Ayrıca dışa açıklık endeksi ile ekolojik ayak izi arasında da istatistiki olarak anlamlı bir ilişki elde edilememiştir.

Tablo 5. Kısa ve Uzun Dönem Katsayı Sonuçları

\begin{tabular}{|c|c|c|}
\hline \multicolumn{3}{|c|}{ Bağımlı Değişken: EF } \\
\hline Değişkenler & Katsayı & t-istatistiği \\
\hline \multicolumn{3}{|c|}{ Kısa Dönem Sonuçları } \\
\hline$\Delta \operatorname{In} Y$ & $6.049 * * *$ & 7.067 \\
\hline$\Delta \operatorname{In} Y^{2}$ & $-2.909 * * *$ & -7.039 \\
\hline$\Delta \operatorname{In} Y^{3}$ & $0.464 * * *$ & 7.008 \\
\hline$\Delta I n C o r$ & $1.323 * *$ & 2.543 \\
\hline$\Delta \operatorname{InT}$ & $-0.115 * * *$ & -3.589 \\
\hline ECT(-1) & $-1.437 * * *$ & -11.194 \\
\hline \multicolumn{3}{|c|}{ Uzun Dönem Sonuçları } \\
\hline $\operatorname{In} Y_{t}$ & -2.231 & $-3.019 * *$ \\
\hline $\operatorname{In} Y^{2}{ }_{t}$ & 1.081 & $3.031 * *$ \\
\hline $\operatorname{In} Y^{3}{ }_{t}$ & -0.174 & $-3.044 * *$ \\
\hline InCor $_{t}$ & 1.051 & 1.097 \\
\hline $\operatorname{In} T_{t}$ & -0.124 & -1.763 \\
\hline Teşhis Testleri & F-istatistiği & Olasılik \\
\hline Serial & 1.237 & 0.381 \\
\hline$A R C H$ & 0.038 & 0.847 \\
\hline Normality & 0.488 & 0.783 \\
\hline CUSUM & İstikrarlı & \\
\hline CUSUMQ & İstikrarl1 & \\
\hline
\end{tabular}


Kısa ve uzun dönemli katsayıların incelenmesinin ardından analizler gereği tutarlı sonuçlar elde etmek amacıyla yapılan teşhis testleri sonuçlarına bakıldığında, Breusch-Godfrey LM testi sonucu modelde otokorelasyon sorunu olmadığ tespit edilmiş, ARCH testi sonucunda ise hata teriminin sabit varyans varsayımını sağladığı sonucuna ulaşılmıştır. Diğer yandan tahmini kalıntıların normallik davranışını tespit etmek amaciyla uygulanan Jarque-Bera testi (JB) sonucuna göre hata teriminin normal dağılıma sahip olduğu, RamseyReset testi ile de doğru fonksiyonel formunun kullanıldığ sonucuna ulaşılmıştır. Ayrıca CUSUM ve CUSUMQ (Cumulative sum and cumulative sum of squares) testleri sonuçlarına göre katsayıların istikrarlı oldukları tespit edilmiştir.

\section{Sonuç ve Politika Önerileri}

Bu çalışmada Türkiye'de 1995-2016 gözlem aralığ1 için yolsuzluğun çevre kirliliği üzerindeki etkileri ARDL sınır testi yaklaşımı ile incelenmiştir. Bu doğrultuda ekonomik büyümenin ekolojik ayak izi üzerindeki doğrusal etkilerinin yanı sıra olası parabolik ve kübik etkileri de incelenmiş, ekonomik büyüme ve ekolojik ayak izi arasındaki ilişki EKC hipotezi çerçevesinde test edilmiştir. Diğer yandan dişa açılık endeksinin de modele dahil edilmesi ile ekonomik büyümenin, dışa açıklık endeksinin ve yolsuzluk endeksinin ekolojik ayak izi üzerindeki etkileri araştırılmıştır.

Çalışmada elde edilen bulgular neticesinde kısa dönemde kişi başına reel GSYİH'nın önce çevre kirliliğini artırdığı, kişi başına reel GSYİH'nın karesinin çevre kirliliğini azalttığı ve sonrasında ise kişi başına reel GSYİH'nın küpünün pozitif işarete sahip olması nedeniyle ekonomik büyüme ile ekolojik ayak izi arasında $\mathrm{N}$-şeklinde bir ilişkinin varlığı tespit edilmiştir. Dışa açıklık endeksinin kısa dönemde ekolojik ayak izi üzerinde negatif bir etkiye sahip olduğu dolayısıyla kısa dönemde dışa açıklık endeksinin çevre kirliliğini azalttığına dair bulgular elde edilmiştir. Halıcıoğlu (2009) ve Doğan ve Turkekul (2016) çalışmalarında dışa açıklık endeksi katsayısının işareti konusunda belirsizliğin söz konusu olduğunu ve bu durumun genellikle ekonominin kalkınma aşamasına bağlı olmasından kaynaklandığını ileri sürmüşlerdir. Ayrıca dışa açıklık endeksi ile ilgili olarak elde edilen bulgular Doğan ve Turkekul (2016), Destek vd. (2016), Zhang vd. (2017)'nin çalışmalarında elde ettiği bulgularla örtüşmekte, bu çalışmalarda da dışa açıklık endeksinde meydana gelen bir birimlik artışın çevre kirliliğinde azalmaya neden olduğu ifade edilmektedir. Diğer yandan yolsuzluk endeksi katsayısının ekolojik ayak izi üzerinde pozitif bir etkiye sahip olması ve dolayısıyla yolsuzluğun çevre kirliliğini artırdığı yönünde bulgular elde edilmiştir. Chen vd. (2018), Balsalobre-Lorente vd. (2019) ve Sinha vd. (2019) çalışmalarında elde edilen bulgularla örtüşen bu sonuç, kamudaki yolsuzluğun çevresel etkinliğin azalmasına ve bunun neticesinde çevre kirliliğine yol açmasıyla sonuçlanmasına neden olduğunu göstermektedir. Diğer yandan uzun dönemli sonuçlar değerlendirildiğinde ekonomik büyüme ile çevre kirliliği arasında kısa dönemin aksine Sinha vd. (2019) çalışmasında da olduğu gibi ters Nşeklinde bir ilişki tespit edilmiştir. Uzun dönemde uygulanan çevresel düzenlemelerin ekonomik büyümeyle birlikte etkinliğinin de arttığı görülmektedir. Diğer yandan uzun dönemde dışa açıklık endeksi ve yolsuzluk değişkenlerinin katsayısının istatistiki olarak anlamsız olduğu sonucuna varılmıştır. Kamu kurumlarında yaşanılan yolsuzluk olayları, kurumların etkinsiz çalışması, sanayi ve kamu kurumlarında çevresel maliyetlerden kaçınmak amacıyla daha ucuz ve yasa dışı yolların tercih edilmesi kirlilik kontrol yasalarının etkinliğini zayıflatmaktadır. Ancak emisyon azaltımını öngören Paris Anlaşması gibi uluslararası anlaşmaların uygulanmaya konmasının ya da uyum kriterleri gibi nedenlerle söz konusu denetimlerin arttırılmasının ve çevresel düzenlemelerin daha kapsayıcı hale getirilmesinin kısa dönemdeki olumsuz etkinin uzun dönemde ortadan kalkmasına neden olduğu söylenebilir. Bu doğrultuda, çevre politikalarının uygulanmasında yolsuzluğun dikkate alınması, bu durumun önüne geçebilecek önlemlerin alınması ve böylece politikaların daha sağlam ve etkili hale getirilmesi gerekmektedir. Ayrica emisyon ticaretinde yolsuzluğun önlenmesi ya da yolsuzlukla mücadele adına atılan önemli adımların yetkililere baskı uygulaması, yolsuzluğun çevre düzenlemeleri üzerindeki baskısını da sınırlandırılmış olacaktır. $\mathrm{Bu}$ uygulamaların faaliyete geçebilmesi amaciyla öncelikle temiz çevre bilincinin oluşturulması ve gerekirse yasal yollarla cezai yaptırımların artırılması gerekmektedir.

\section{Kaynakça}

Ahmad, N., Du, L., Lu, J., Wang, J., Li, H. Z., \& Hashmi, M. Z. (2017). Modelling the Co2 emissions and economic growth in Croatia: is there any environmental kuznets curve? Energy, 123, 164-172.

Al-Mulali, U., Weng-Wai, C., Sheau-Ting, L., \& Mohammed, A. H. (2015). Investigating the environmental kuznets curve (ekc) hypothesis by utilizing the ecological footprint as an indicator of environmental degradation. Ecological Indicators, 48, 315-323.

Al-Mulali U, Ozturk I, \& Solarin SA. (2016) Investigating the environmental kuznets curve hypothesis in seven regions: the role of renewable energy. Ecol Indic 67:267282.

Anser, M. K., Alharthi, M., Aziz, B., \& Wasim, S. (2020). Impact of urbanization, economic growth, and population size on residential carbon emissions in the SAARC countries. Clean Technologies and Environmental Policy, 1-14.

Aslan, A., Destek, M. A., \& Okumus, I. (2018). Sectoral carbon emissions and economic growth in the US: further evidence from rolling window estimation method. Journal of Cleaner Production, 200, 402-411.

Balsalobre-Lorente, D., Shahbaz, M., Jabbour, C. J. C., \& Driha, O. M. (2019). The role of energy innovation and corruption in carbon emissions: evidence based on the ekc hypothesis. Energy and Environmental Strategies in the Era of Globalization (pp. 271-304). Springer, Cham.

Bölük, G. \& Mert, M. (2015). The renewable energy, growth and environmental kuznets curve in Turkey: an ARDL approach. Renewable and Sustainable Energy Reviews, 52, 587-595.

Charfeddine, L., \& Mrabet, Z., (2017). The impact of economic development and social-political factors on 
ecological footprint: a panel data analysis for 15 MENA countries. Renew. Sustain. Energy Rev. 76, 138-154.

Chen, H., Hao, Y., Li, J., \& Song, X. (2018). The impact of environmental regulation, shadow economy, and corruption on environmental quality: theory and empirical evidence from China. Journal of Cleaner production, 195, 200-214.

Cho, C. H., Chu, Y. P. \& Yang, H. Y. (2014). An environment kuznets curve for ghg emissions: a panel cointegration analysis. Energy Sources, Part B: Economics, Planning, and Policy, 9(2), 120-129.

Çetin, M., Ecevit, E., \& Yucel, A. G. (2018). The impact of economic growth, energy consumption, trade openness, and financial development on carbon emissions: empirical evidence from Turkey. Environmental Science and Pollution Research, 25(36), 36589-36603.

Damania, R., P.G. Fredriksson, \& J.A. List (2003), Trade liberalization, corruption and environmental policy formation: theory and evidence, Journal of Environmental Economics and Management 46: 490512.

Desai, U. (ed.) (1998), Ecological policy and politics in developing countries: growth, democracy and environment, Albany: State University of New York Press.

Destek, M. A. \& Ozsoy, F. N. (2015). Relationships between economic growth, energy consumption, globalization, urbanization and environmental degradation in Turkey. International Journal of Energy and Statistics, 3(4), 113.

Destek, M. A., Balli, E., \& Manga, M. (2016). The relationship between co2 emission, energy consumption, urbanization and trade openness for selected CEECs. Research in World Economy, 7(1), 52-58.

Destek, M. A., Ulucak, R., \& Dogan, E. (2018). Analyzing the environmental kuznets curve for the EU countries: the role of ecological footprint. Environmental Science and Pollution Research, 25(29), 29387-29396.

Destek, M. A., \& Sarkodie, S. A. (2019). Investigation of environmental kuznets curve for ecological footprint: the role of energy and financial development. Science of The Total Environment, 650, 2483-2489.

Do, T., \& Dinh, H. (2020). Short-and long-term effects of gdp, energy consumption, fdi, and trade openness on co2 emissions. Accounting, 6(3), 365-372.

Dogan, E., \& Turkekul, B. (2016). Co2 emissions, real output, energy consumption, trade, urbanization and financial development: testing the ekc hypothesis for the USA. Environmental Science and Pollution Research, 23(2), 1203-1213.

Dogan, E., \& Inglesi-Lotz, R. (2020). the impact of economic structure to the environmental kuznets curve (ekc) hypothesis: evidence from European Countries. Environmental Science and Pollution Research, 1-8.

Fredriksson, P. G., Vollebergh, H. R., \& Dijkgraaf, E. (2004). Corruption and energy efficiency in OECD countries: theory and evidence. Journal of Environmental Economics and management, 47(2), 207231.

Global Footprint Network, 2017. National footprint accounts, ecological footprint. (Erişim: 25.06.2020). http://data.footprintnetwork.org.

Grossman, G.M. \& A.B. Krueger (1995), Economic growth and the environment, Quarterly Journal of Economics 110: $353-377$.

Hafner, O. (1998), The role of corruption in the misappropriation of tropical forest resources and in tropical forest destruction, Transparency International Working Paper, www.transparency.org/documents/work-papers.

Hervieux, M.-S., \& Darné, O., (2015). Environmental kuznets curve and ecological footprint: time series analysis. Econ. Bull. 35, 814-826

Kahia, M., Omri, A., \& Jarraya, B. (2021). Does green energy complement economic growth for achieving environmental sustainability? evidence from Saudi Arabia. Sustainability, 13(1), 180.

Kasman, A. \& Duman, Y. S. (2015). Co2 emissions, economic growth, energy consumption, trade and urbanization in new EU member and candidate countries: a panel data analysis. Economic Modelling, 44, 97-103.

Kaufmann, D., A. Kraay, \& P. Zoido-Lobaton (1999), governance matters, World Bank Policy Research Working Paper, The World Bank, Washington, DC.

Khan, S. A. R., Zaman, K., \& Zhang, Y. (2016). The relationship between energy-resource depletion, climate change, health resources and the environmental kuznets curve: evidence from the panel of selected developed countries. Renewable and Sustainable Energy Reviews, $62,468-477$.

Kılavuz, E., \& Doğan, İ. (2020). Economic growth, openness, industry and co 2 modelling: are regulatory policies important in Turkish economies?. International Journal of Low-Carbon Technologies.

Lau, L. S., Choong, C. K., \& Eng, Y. K. (2014). Investigation of the environmental kuznets curve for carbon emissions in Malaysia: do foreign direct investment and trade matter?. Energy Policy, 68, 490-497.

Li, T., Wang, Y., \& Zhao, D. (2016). Environmental kuznets curve in China: new evidence from dynamic panel analysis. Energy Policy, 91, 138-147.

Lippe, M. (1999). Corruption and environment at the local level. Transparency International Working Paper. Retrieved March, 31, 2014.

López, R., \& Mitra, S. (2000). Corruption, pollution, and the kuznets environment curve. Journal of Environmental Economics and Management, 40(2), 137-150.

Lucas, R.E., Wheeler, D., \& Hettige, H. (1992). Economic development, environmental regulation, and the international migration of toxic industrial pollution, vol.1062. World Bank Publications, 1960-1988. 
Mrabet, Z., \& Alsamara, M., (2017). Testing the kuznets curve hypothesis for Qatar: a comparison between carbon dioxide and ecological footprint. Renew. Sustain. Energy Rev. 70, 1366-1375.

Murthy, K. V. \& Gambhir, S. (2018). Analyzing environmental kuznets curve and pollution haven hypothesis in India in the context of domestic and global policy change. Australasian Accounting, Business and Finance Journal, 12(2): 134-156.

Narayan PK (2005) The saving and investment nexus for China: evidence from cointegration tests. Appl. Econ 37(17):1979-1990.

Naz, S., Sultan, R., Zaman, K., Aldakhil, A. M., Nassani, A. A., \& Abro, M. M. Q. (2019). Moderating and Mediating Role of Renewable Energy Consumption, FDI Inflows, and Economic Growth on Carbon Dioxide Emissions: Evidence from Robust Least Square Estimator. Environmental Science and Pollution Research, 26(3), 2806-2819.

Ongan, S., Isik, C., \& Özdemir, D. (2020). Economic Growth and Environmental Degradation: Evidence from the US case environmental kuznets curve hypothesis with application of decomposition. Journal of Environmental Economics and Policy, 1-8.

Öztürk, I. \& Acaravc1, A. (2013). The long-run and causal analysis of energy, growth, openness and financial development on carbon emissions in Turkey. Energy Economics, 36, 262-267.

Özturk, I., Al-Mulali, U., \& Saboori, B., (2016). Investigating the environmental kuznets curve hypothesis: the role of tourism and ecological footprint. Environ. Sci. Pollut. Res. 23, 1916-1928.

Özokcu, S., \& Özdemir, O. (2017). Economic growth, energy, and environmental kuznets curve. Renewable and Sustainable Energy Reviews, 72, 639-647.

Panayotou, T., (1993). Empirical tests and policy analysis of environmental degradation at different stages of economic development. International Labour Organization.

Pata, U. K. (2019). Environmental kuznets curve and trade openness in Turkey: bootstrap ardl approach with a structural break. Environmental Science and Pollution Research, 26(20), 20264-20276.

Pearse, R. (2016). The coal question that emissions trading has not answered. Energy Policy 99, 319-328.
Pesaran, M. H., \& Shin, Y. (1998). An autoregressive distributed-lag modelling approach to cointegration analysis. Econometric Society Monographs 31: 371-413.

Ridzuan, N. H. A. M., Marwan, N. F., Khalid, N., Ali, M. H., \& Tseng, M. L. (2020). Effects of agriculture, renewable energy, and economic growth on carbon dioxide emissions: evidence of the environmental kuznets curve. Resources, Conservation and Recycling, 160, 104879.

Rodriguez, P., Uhlenbruck, K. \& Eden, L. (2005). Government corruption and the entry strategies of multinationals. Acad. Manag. Rev. 30(2), 383-396.

Sinha, A., Gupta, M., Shahbaz, M., \& Sengupta, T. (2019). Impact of corruption in public sector on environmental quality: implications for sustainability in BRICS and Next 11 countries. Journal of Cleaner Production, 232, 1379-1393.

Transparency International, (2016). (Erişim: 25.06.2020). https://www.transparency.org/en/cpi/2016.

Ulucak, R., \& Bilgili, F. (2018). a reinvestigation of ekc model by ecological footprint measurement for high, middle and low income countries. Journal of cleaner production, 188, 144-157.

Ulucak, R., \& Khan, S. U. D. (2020). Determinants of the ecological footprint: role of renewable energy, natural resources, and urbanization. Sustainable Cities and Society, 54, 101996.

Uzar, U., \& Eyuboglu, K. (2020). Do natural resources heal the environment? empirical evidence from Turkey. Air Quality, Atmosphere \& Health, 1-10.

Wackernagel, M., \& Rees, W., (1998). Our ecological footprint: reducing human impact on the earth. New Society Publishers.

World Bank, 2016. World development indicators. (Erişim: 25.06.2020). http://data.worldbank. org/country.

Yilanci, V., \& Pata, U. K. (2020). investigating the ekc hypothesis for China: the role of economic complexity on ecological footprint. Environmental Science and Pollution Research International.

Zhang, S., Liu, X., \& Bae, J. (2017). Does trade openness affect co2 emissions: evidence from ten newly industrialized countries?. Environmental Science and Pollution Research, 24(21), 17616-17625. 


\section{Extended Abstract}

In recent years, it is seen that climate change and global warming problems have led to an increase in the awareness of the clean environment and it has become an important subject in which the effects of especially economic activities on environmental pollution are investigated. From this point of view, it is seen that the relationship between economic growth and environmental pollution is examined within the framework of the Environmental Kuznets Curve (EKC) (Doğan and Inglesi-Lotz, 2020; Ongan et al., 2020; Do and Dinh, 2020). The validity of the EKC hypothesis has been investigated by many researchers with $\mathrm{CO} 2$ emission, which is an important indicator of environmental damage (Aslan et al., 2018; Balsalobre-Lorente et al., 2019; Ridzuan et al., 2020 Anser et al.2020). However, the ecological footprint developed by Wackernagel and Rees (1998) has been accepted as a more comprehensive indicator for determining the degree of environmental degradation. Thus, it is seen that studies that examine the relationship between ecological footprint and economic growth have recently been emphasized. Considering the studies that examine the factors causing environmental damage, the effects of the pollution resulting from economic growth, openness index or excessive consumption of natural resources are mainly investigated. Besides, it is observed that the concept of corruption, which is frequently encountered especially in public institutions, is neglected.

The concept of corruption has started to be mentioned not only in the economic field but also in the field of environmental economics. It is argued that the reasons such as resilience in strict environmental protection policies, excessive advantage to preferred companies, or putting environmental protection policies into the background after industrialization, especially in developing economies, cause corruption practices. On the other hand, there are studies that reveal that the disruptions caused by the strict management of environmental protection laws may be related to environmental damage (Lucas et al., 1992; Rodriguez et al., 2005). In addition, Lippe (1999), examining the relationship between corruption and environmental pollution, stated that corruption can lead to environmental pollution by causing ineffectiveness in the implementation of environmental laws.

The possible contributions to the literature of the study are: i) the impact of environmental pollution on corruption in Turkey is known to be the first study which examined. ii) while creating the empirical model, the variables of economic growth and openness index are not ignored to take into account their effects on environmental pollution. iii) In this study, which examines the relationship between corruption and environmental pollution, the ecological footprint, which is an important indicator of environmental damage, and the validity of the EKC hypothesis were tested with the ARDL boundary test approach.

For this reason, in this study, the effect of the corruption in the public sector on environmental pollution is examined in Turkey during 1995-2016 by applying ARDL bounds testing approach. In addition to the linear effects of economic growth on the ecological footprint, possible parabolic and cubic effects are also examined, and the relationship between economic growth and ecological footprint is tested in the framework of the EKC hypothesis. In addition, the effects of trade openness index and corruption index on environmental pollution are investigated. In the short term, the N-shaped relationship has been detected between economic growth and environmental pollution. It is concluded that the trade openness index has a negative effect on the ecological footprint and corruption increases environmental pollution. In the long term, the inverse $\mathrm{N}$-shaped relationship has been found between economic growth and environmental pollution. It is concluded that the coefficient of trade openness index and corruption are statistically insignificant.

It is observed that the effectiveness of environmental regulations applied in the long term increases with economic growth. On the other hand, it is concluded that the coefficient of openness index and corruption variables are statistically insignificant in the long run. Corruption in public institutions, inefficient operation of institutions, and the use of illegal ways to avoid environmental costs in industry and public institutions weaken the effectiveness of pollution control laws. However, it can be said that the implementation of international agreements such as the Paris Agreement, which envisages emission reduction, increased inspections for reasons such as compliance criteria and made environmental regulations more inclusive cause the negative effect in the short term to disappear in the long term. In this direction, it is necessary to consider corruption in the implementation of environmental policies, to take measures to prevent this situation and thus to make the policies more robust and effective. In addition, important steps taken in the name of preventing or combating corruption in emissions trading will put pressure on the authorities, which will limit the pressure of corruption on environmental regulations. In order for these practices to become operational, first of all, it is necessary to create a clean environment awareness and, if necessary, to increase legal sanctions. 